\title{
Mental health and psychological impacts from the 2011 Great East Japan Earthquake Disaster: a systematic literature review
}

\author{
Nahoko Harada ${ }^{1,2^{*}}$, Jun Shigemura ${ }^{3}$, Masaaki Tanichi ${ }^{3}$, Kyoko Kawaida$^{1}$, Satomi Takahashi ${ }^{1}$
} and Fumiko Yasukata'

\begin{abstract}
Background: On March 11,2011, Japan experienced an unprecedented combination of earthquake/tsunami/ nuclear accidents (the Great East Japan Earthquake; GEJE). We sought to identify mental health and psychosocial consequences of this compound disaster.

Method: A systematic literature review was conducted of quantitative research articles addressing mental health of survivors and the psychological impact of the GEJE. For articles between March 2011 and December 2014, PubMed, PsychINFO, and EMBASE databases were searched with guidance on literature review method.
\end{abstract}

Results: Forty-nine studies met the inclusion criteria. A substantial proportion of the affected individuals experienced considerable psychological distress. Mental health outcomes included, but were not limited to, posttraumatic stress disorder, depression, and anxiety symptoms. Physical health changes, such as sleeping and eating disturbances, also occurred. In Fukushima, radioactive release induced massive fear and uncertainty in a large number of people, causing massive distress among the affected residents, especially among mothers of young children and nuclear plant workers. Stigma was additional challenge to the Fukushima residents. The review identified several groups with vulnerabilities, such as disaster workers, children, internally displaced people, patients with psychiatric disorders, and the bereaved.

Conclusions: Following the GEJE, a considerable proportion of the population was mentally affected to a significant degree. The affected individuals showed a wide array of mental and physical consequences. In Fukushima, the impact of nuclear disaster was immense and complex, leading to fear of radiation, safety issues, and stigma issues.

Keywords: Disaster, Mental health, Psychological service, Posttraumatic stress disorder, Great East Japan Earthquake, Earthquake, Tsunami, Fukushima Daiichi nuclear accident, Radiation fear

\section{Background}

On March 11, 2011, a 9.0-magnitude mega-earthquake hit the islands of Japan at 2:46 pm local time. This earthquake was the strongest recorded earthquake in the country's modern history [1]. The earthquake's epicenter

\footnotetext{
*Correspondence: nahoko-harada@umin.ac.jp

${ }^{1}$ Division of Nursing, School of Medicine, National Defense Medical

College, 3-2 Namiki, Tokorozawa, Saitama 359-8513, Japan

Full list of author information is available at the end of the article
}

was located approximately $80 \mathrm{~km}$ off the northeastern (Tohoku) region of the island of Honshu, the country's main island. Repeated aftershocks and towering tsunami waves occurred after the mega-earthquake; the tsunami waves were as high as $40 \mathrm{~m}$ above sea level and reached $10 \mathrm{~km}$ inland (Fig. 1) [2]. A large majority of the damage occurred in three prefectures in the Tohoku area: Iwate, Miyagi, and Fukushima (Fig. 2). As of December 10,2014 , the numbers of dead, missing, or injured were $15,889,2594$, and 6152, respectively [3]. 


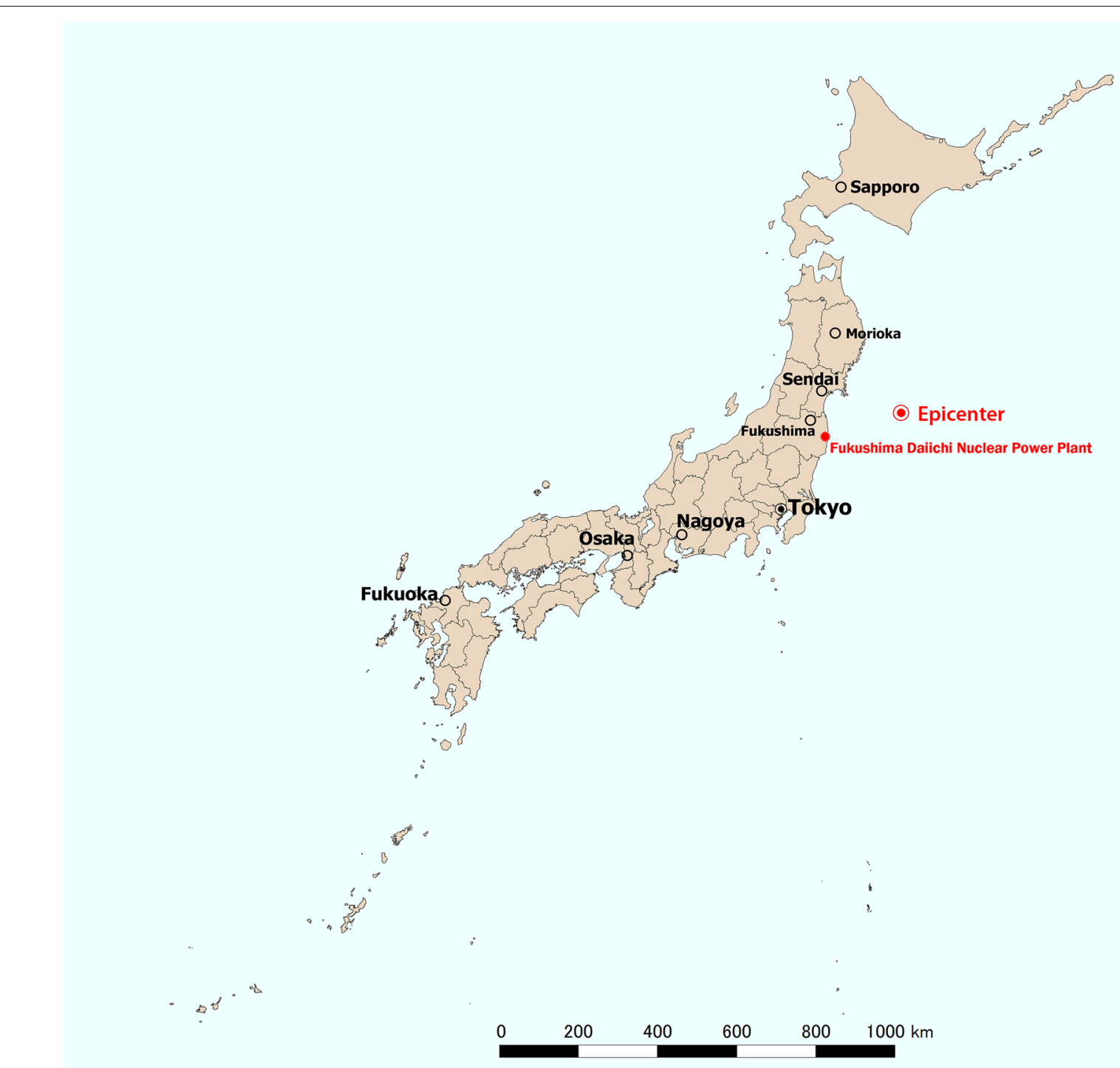

Fig. 1 Locations of earthquake epicenter of the 2011 Great East Japan Earthquake and major cities

In Fukushima, the earthquakes and tsunamis triggered a nuclear accident at Tokyo Electric Power Company (TEPCO) Fukushima Daiichi Nuclear Power Plant. Between March 11 and 15, 2011, four of the six reactors experienced explosions, and three reactors escalated to nuclear meltdown and released radioactive materials, requiring a mandatory evacuation of the surrounding region. This crisis became the largest nuclear accident since the 1986 Chernobyl nuclear disaster, and the second accident, after Chernobyl, to measure Level 7 on the International Nuclear Event Scale.

On March 12, 2011, the Japanese government ordered mandatory evacuation of residents in the $20 \mathrm{~km}$ radius of the nuclear plant. As of December 2014, more than 121,000 residents are still on evacuation status [4]. Although there have been no fatalities owing to radiation exposure, safety concerns related to nuclear contamination created enormous fear, burden, and disruption to individuals, groups, communities, and local/national governments. These series of disasters were eventually named as the Great East Japan Earthquake (GEJE).

When evaluating post-disaster outcome studies, it must be noted every disaster is different in the terms of disaster type (e.g., natural, technological, manmade), location (e.g., developed vs. developing country), population (e.g., adults vs. children), intensity (life-threatening vs. non-), 


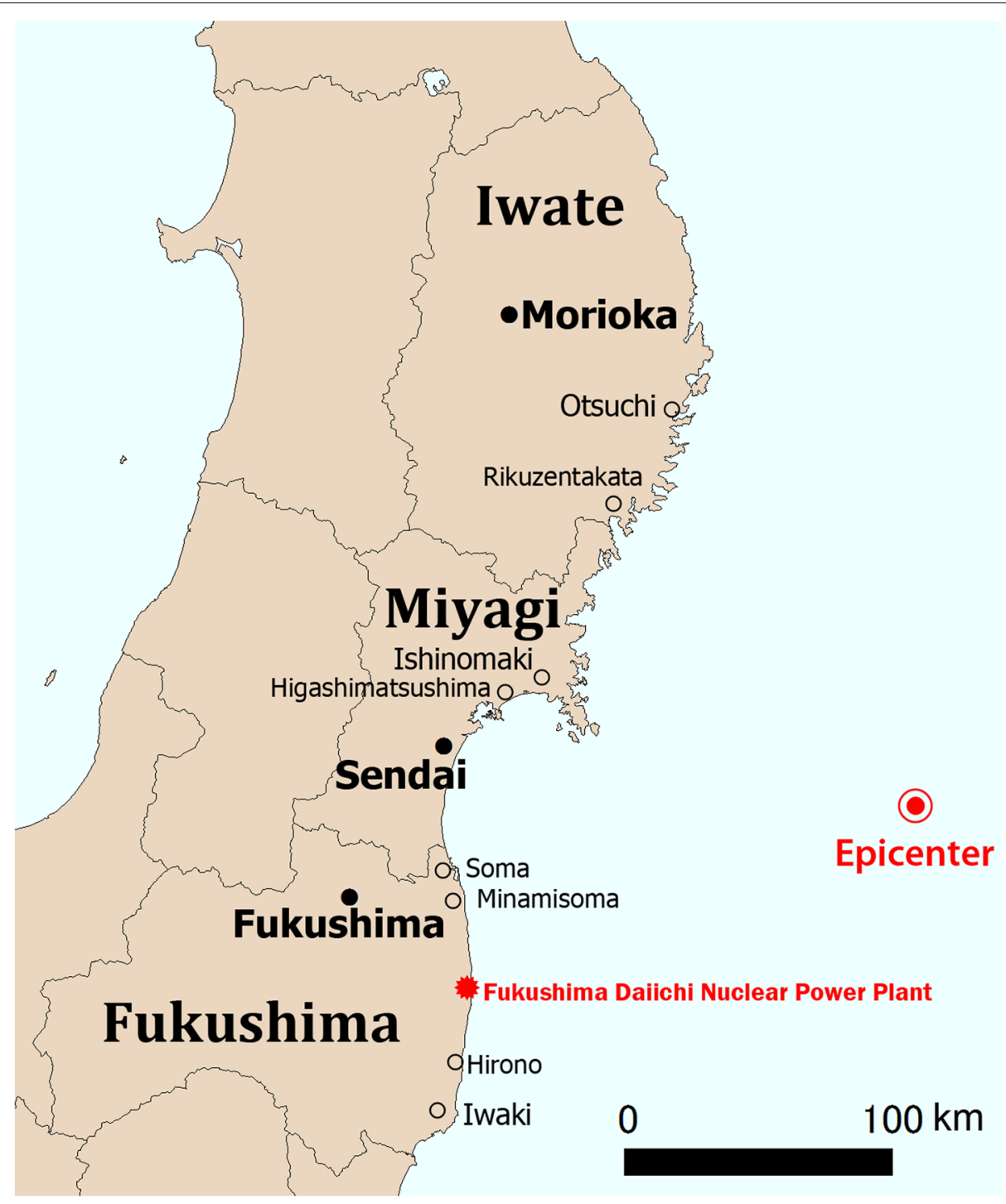

Fig. 2 Three severely affected prefectures of the Tohoku region, Japan; Iwate, Miyagi, and Fukushima

exposure frequency (e.g., single vs. repeated experiences), and many other medical/social/economic conditions. It is also very rare to randomize study samples or to have pre-disaster comparison [5].

Given these limitations, researches have shown a large majority of the people affected by disasters is resilient and will fully recover from their traumatic experiences [6]. A small portion of the affected individuals will result in a wide range of mental, behavioral, and physical health consequences [e.g., depression, posttraumatic stress disorder (PTSD) and other anxiety disorders, suicidal behaviors, alcohol misuse, and sleep disturbances]. Studies also have highlighted at-risk populations for adverse outcomes, such as female gender, preexisting psychiatric illnesses, presence of children in the home, secondary stressors, and low psychosocial resources [5-7]. Disaster workers, exposed to a variety of traumatic exposure through their work roles, are of significant concern when considering post-disaster mental health [5]. This trend was true for the Chernobyl first responders and cleanup workers as well; their depression and PTSD rates remained high two decades later [8].

A wide majority of these studies revealed the impact on mental health and psychosocial aspects of one particular event (e.g., man-made or natural). However, in the case of large-scale compound disasters, the epidemiological data are scarce. As of writing, GEJE mental health studies are evolving, but scientific review of this disaster's mental 
health studies is warranted to increase better understanding of psychosocial outcomes of the people affected by the GEJE.

The aims of this article are to (1) consolidate quantitative and qualitative studies examining mental health and psychosocial impacts in people affected by the GEJE, (2) identify their mental health and psychosocial consequences, (3) ascertain vulnerable populations, and (4) elucidate factors that impact mental health and psychosocial outcomes in populations affected by the earthquake.

\section{Methods}

A systematic literature review was conducted of quantitative research articles addressing mental health of survivors and the psychological impact of the 2011 GEJE between March 2011 and December 2014. PubMed, PsychINFO, and EMBASE databases were searched with guidance on literature review method [9]. The searched keywords included Great East Japan Earthquake Disaster, Japan, disaster, health, mental health, psychological, impact, stress, trauma, bereavement, and grief and these items were used either alone or in combination.

All identified articles were examined with the title and abstract whether the article specifically addresses mental health and psychosocial issues related to the GEJE by the investigators ( $\mathrm{NH}$ and JS). If the abstract unclearly described the study aims, method, or results, $\mathrm{NH}$ and JS read the article to determine the relevance of the article. Studies written in a language other than English, situational reports, activity reports, conference reports/ abstracts/summaries, letters to the editor (including replies), and bulletins from universities or private organizations were not included in this review. To ensure inclusiveness, the other authors of the current article were encouraged to search for articles manually and, if additional articles met the inclusion criteria, such articles were also included for review.

A total of 382 studies were identified, with 49 articles meeting the inclusion criteria. The identified articles were categorized by four main research topics: (1) mental health outcomes among affected populations (excluding Fukushima), (2) Fukushima resident studies, (3) disaster and support worker researches, and (4) grief studies. We decided to separate the first two topics because of the uniqueness of nuclear disaster and a potentially profound mental health impact among the affected people.

\section{Results}

Table 1 summarizes the study results of mental health outcomes among the affected populations (excluding Fukushima). A total of 28 articles met this inclusion criterion [10-37]. A majority of the study populations were from Miyagi and Iwate [15 (53.6\%) and 3 (10.7 \%), respectively]. Other studies included subjects from the Ibaraki, Tochigi, Tokyo, among others. A major portion of the studies were cross-sectional. Regarding outcome measures, nine (32.1\%) studies addressed PTSD, six $(21.4 \%)$ assessed general psychological distress, two (7.1\%) examined depressive symptoms. Other outcomes included anxiety, sleep disturbance, social functioning, social isolation, admission rates, suicide rates, and cerebral structure changes.

Table 2 compiles the 12 study results reporting psychosocial consequences of the individuals affected by the Fukushima nuclear disaster [38-49]. Adverse outcome measures were primarily general psychological distress, symptoms of PTSD, depression, as well as anxiety disorders, especially in context with radiation fear. Other outcomes represented the uniqueness of a nuclear disaster, such as concern of radiation and food safety [43, 49], maternal anxiety (including food safety, outdoor safety, radiation effects on embryos, economic issues, distrust towards information disclosure) [47, 49], lowered maternal confidence [47], and stigma owing to their radiation exposures [48].

Table 3 represents eight study outcomes of GEJE disaster and support workers [50-57]. Their outcomes measures were general psychological distress as well as symptoms of PTSD or depression. Of note, a study of Fukushima nuclear plant workers showed discrimination/slurs experience as a key factor for their mental health consequences [56]. This trend was associated with the public criticism to the electric company's post-disaster management. One study focused on potential of fish oil in attenuating PTSD symptoms among DMAT (Disaster Medical Assistant Team) medical workers [53].

Table 4 shows a result of a sole study examining the grief responses affected by the GEJE [58]. This study showed the distinctiveness of complicated grief from symptoms of PTSD or depression. Other articles, not listed in the table, were leaned on narratives and support activity reports. For example, our co-author (ST) launched a support group immediately after the disaster for people in grief and bereavement [59]. This support group aims to (1) provide information about grief, the concept of which is not as popularly known in Japan (much like PTSD), and (2) provide training sessions and workshops in collaboration with the local grief support organizations.

\section{Discussions}

Our review compiled a wide array of mental health consequence following the GEJE, an unprecedented compound disaster with a combination of earthquakes, tsunamis, and a series of nuclear accidents. A 


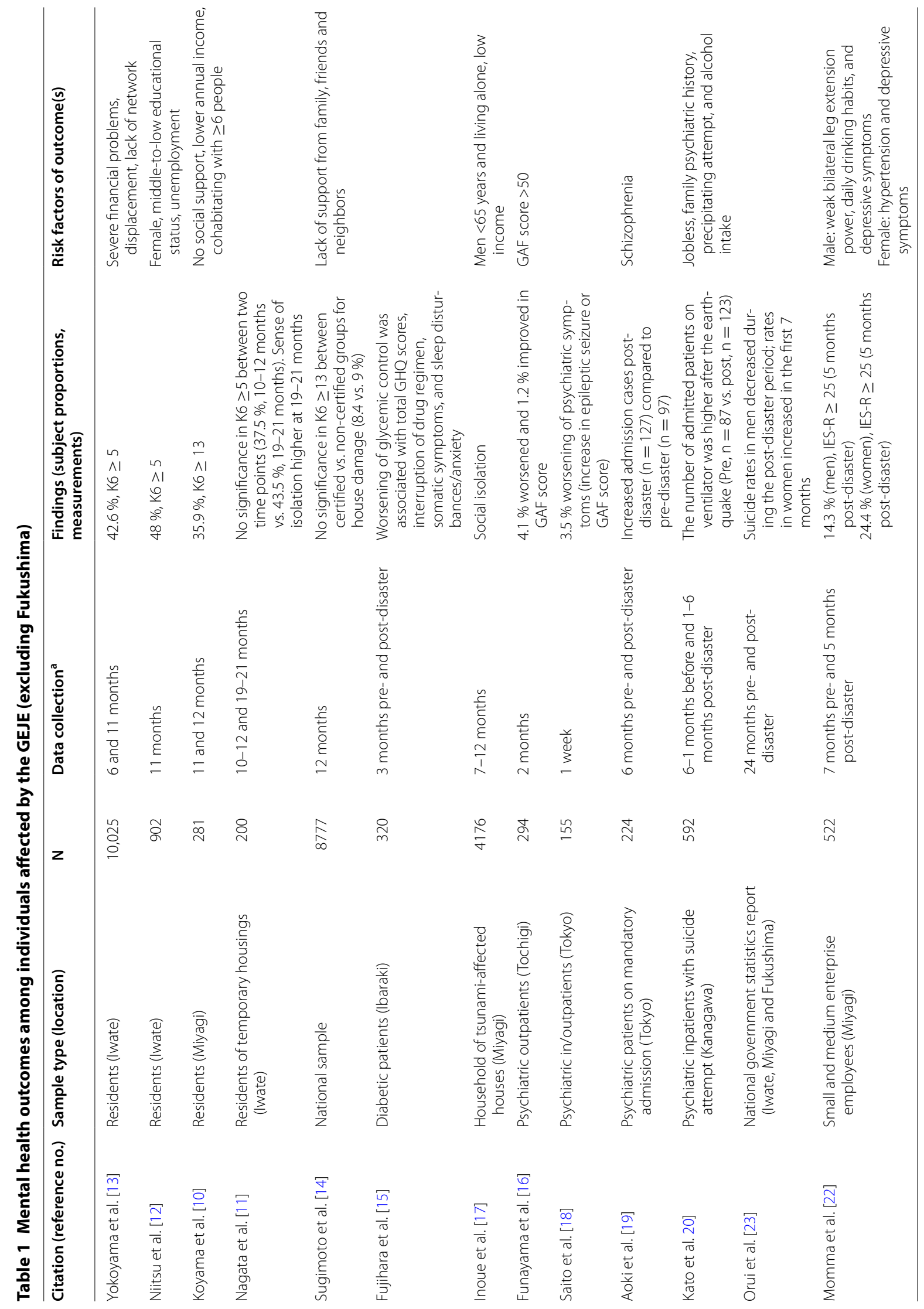




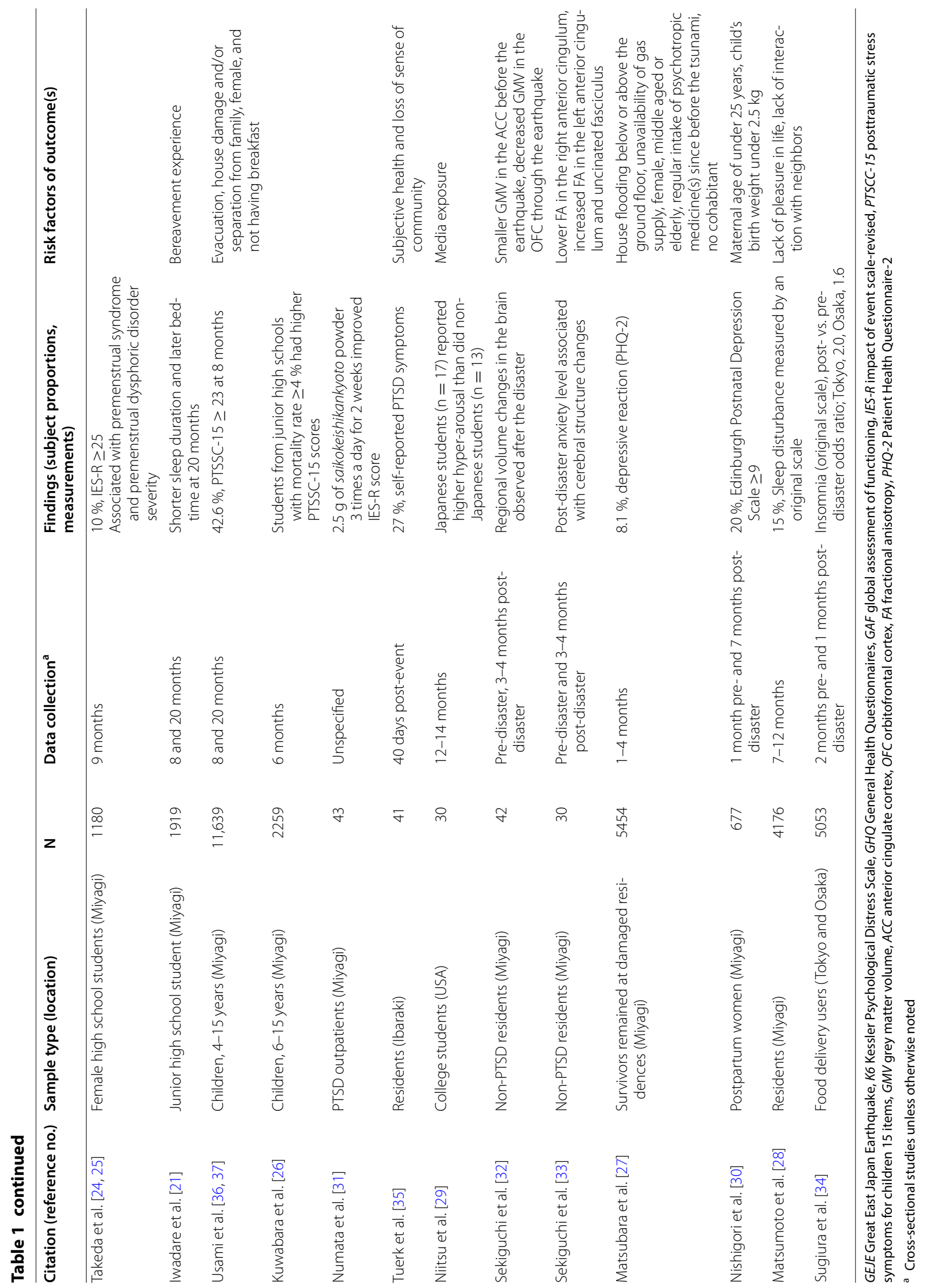




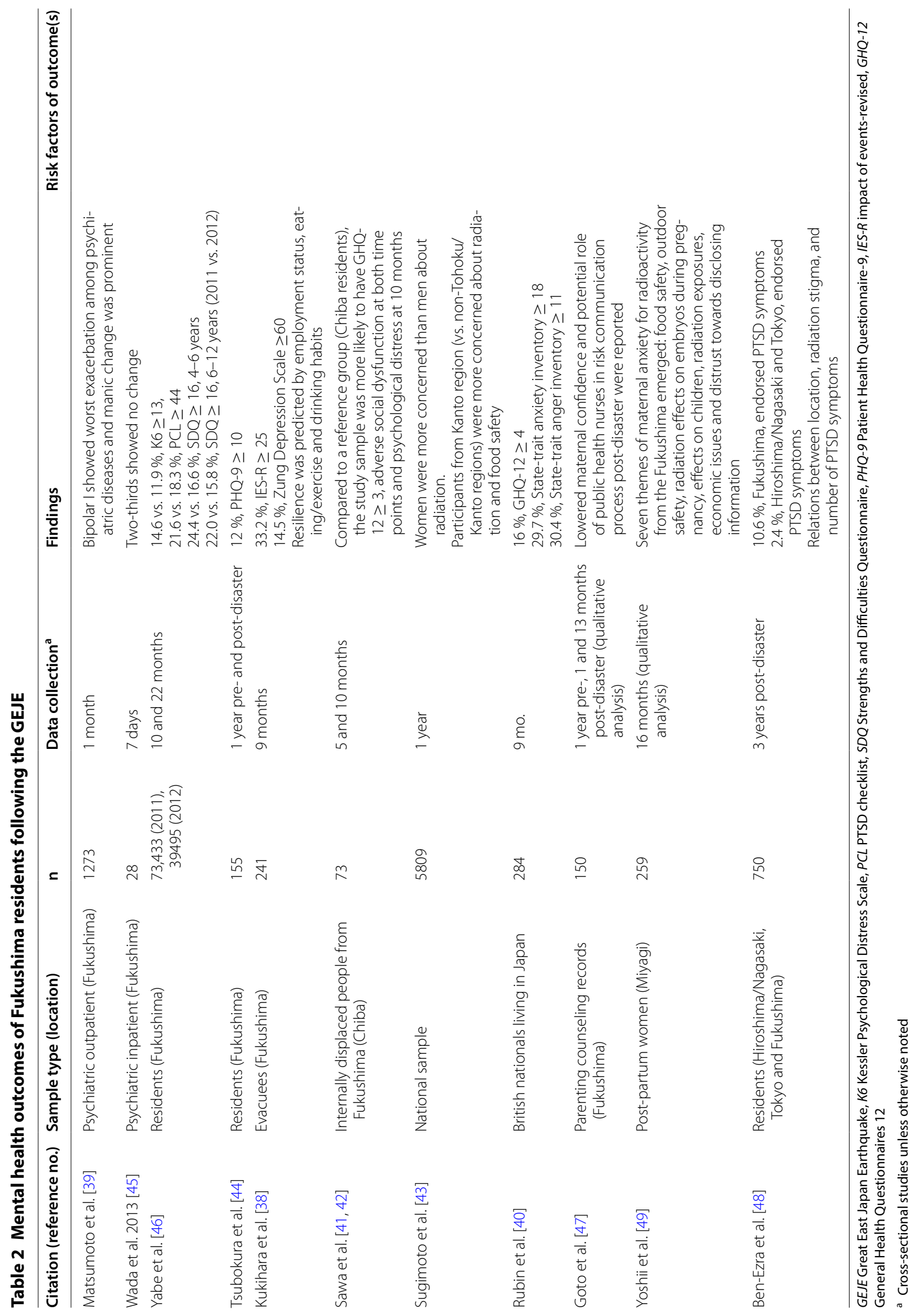




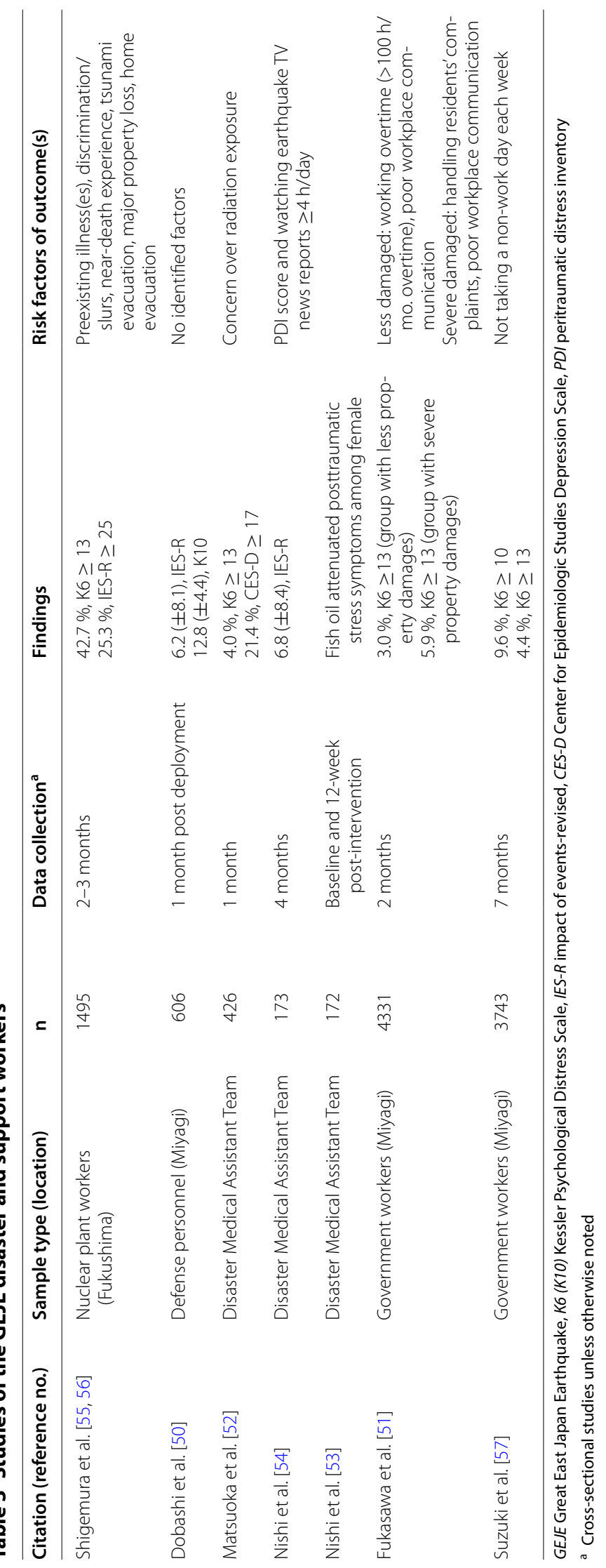


Table 4 Grief study following the GEJE

\begin{tabular}{|c|c|c|c|c|c|}
\hline Citation (reference no.) & Sample type (location) & $\mathrm{N}$ & Data collection $^{a}$ & Findings & $\begin{array}{l}\text { Risk factors } \\
\text { of outcome(s) }\end{array}$ \\
\hline Tsutsui et al. [58] & $\begin{array}{l}\text { Hospital workers } \\
\text { (tsunami-affected area) }\end{array}$ & 82 & 8 months & $\begin{array}{l}9.8 \%, I C G \geq 25 \\
29.3 \%, I E S-R \geq 25 \\
37.8 \%, C E S-D \geq 16 \\
\text { Prolonged grief disorder in qualita- } \\
\quad \text { tively distinct from PTSD and major } \\
\text { depressive disorder }\end{array}$ & \\
\hline
\end{tabular}

GEJE Great East Japan Earthquake, ICG Inventory of Complicated Grief, IES-R impact of events-revised, CES-D Center for Epidemiological Studies Depression Scale

${ }^{a}$ Cross-sectional studies unless otherwise noted

considerable proportion of the study population was mentally affected to a substantial degree, and mental health responses ranged from approximately one-tenth to nearly half of the respondents [12, 27]. Mental health outcomes included, but were not limited to, PTSD, depression, and anxiety. Physical health changes, such as sleep and eating disturbances, were also reported.

Although every disaster is different, disasters are large-scale, stressful, and distressing events that affect a significant number of people. Those who experience higher exposure to traumatic events are likely to show higher mental health responses (i.e., dose-response relationship) [60]. For the most people, these acute responses are normal and gradually decrease over time, but a small proportion of the affected individuals will suffer long-term mental health issues. In a review of 160 disaster mental health studies, proportions of subjects with severe impairment were $21.6 \%$ for natural disasters and $18.5 \%$ for technological disaster samples [6]. The articles in this review had relatively higher mental health rates than in previous studies. This trend might be related to the high impact of this disaster as well as the GEJE study timing, because most of the studies were conducted among the direct victims within 2 years after the disaster. Long-term, longitudinal studies are evolving, and they will potentially be useful to understand the trajectories of mental health consequences among these people.

In the region affected by the Fukushima nuclear disaster, invisible and imperceptible nature of radioactive materials has been challenged among the affected people. The residents' responses were diverse and complex; along with high proportions of mental health distress among the Fukushima residents [46], concerns for radiation effect were a prominent concern especially among pregnant women and mothers of young children [43, 49, 61]. Safety issues in food and outdoor activities, along with economic issues and distrust in information disclosure were also reported [43, 49]. Public psychosocial responses such as discrimination and stigmatization were also reported $[48,56]$.

These findings are in accordance with a series of Chernobyl studies where a complex relationship between radiation exposure and physical/mental health effect has been an ongoing debate. Physical outcome studies tend to be controversial, although firm evidence can be found only on the deaths of first responders due to acute radiation exposures and high prevalence of thyroid cancer among the exposed children [8]. Still, psychosocial and economic disruptions to the affected people were significant, and the International Atomic Energy Agency regarded mental health as the major public health sequelae of the Chernobyl accident [62]. Mothers of young children and plant clean-up workers were among the two groups of particular concern [63-65]. Psychosocial issues included not only mental health disorders but also stigmatization and discrimination of the affected people [8], suggesting the importance of integrity and accuracy of information as well as risk communication strategies.

Two Fukushima studies reported distress among internally displaced people [38, 41]. Mandatory evacuation measures have been in place for the area surrounding the nuclear plant, and the evacuees potentially have uncertain and ambiguous perspectives on whether or not they will be able to return home [66]. This trend was also compatible with Chernobyl studies reporting challenges in evacuation and resettlement [8]. Future studies will be essential to clarify the effect of evacuation following nuclear disasters.

Fukushima and Chernobyl studies suggest that substantial public health efforts are crucial to establish a system capable of such exposures. Integrity and accuracy of information will be a critical issue for the public to assess their health status. These studies also have implications for other "tangible" disasters, such as emergencies related to bio-chemical weapons and infectious diseases [67]. Long-term studies will be important to increase the psychosocial impact among Fukushima residents, with 
special focus on children, mothers, and nuclear plant workers.

A number of studies assessed a considerable degree of mental distress among disaster workers. This is likely to be owing to work-related exposures of these workers. In the case of GEJE, many of the workers were also local disaster victims, and had struggles as survivors along with their work-related exposures. This effect was prominent in several studies $[51,56,57]$. Two worker studies identified experiences of being discriminated against and handling residents' complaints as risk factors for their adverse mental health $[56,57]$. In the former study, the Fukushima nuclear plant workers became targets of public criticism because their company was blamed for their post-disaster mismanagement. In the latter, Miyagi Prefecture workers received direct complaints from their residents in a chaotic situation. These results might give hypotheses that mental health of disaster workers is susceptible to their stakeholder's criticisms.

Past literatures identified mortuary work as predictors of PTSD or physical symptoms among disaster workers $[68,69]$, but in our review, there has yet be an evidence that mortuary work was associated with adverse mental health $[50,51]$. Further studies will be needed to elucidate the relationship between dead body exposure and mental health outcomes among this population.

Previous studies highlighted vulnerable populations for post-disaster mental health, such as children, evacuees, the bereaved, and individuals with preexisting physical/ mental health conditions $[5,6]$. Our compilation overall shows a similar trend, although studies are relatively few, especially in the context of grief.

We recognize several limitations of this paper. The GEJE, especially the Fukushima nuclear accident, is an ongoing disaster, and new studies are emerging. Given the timing and methodology of our literature search, we were not able to include narrative studies, non-English papers, or papers describing long-term disaster impact. Although we made every possible effort to include all related studies, some studies may have been inadvertently omitted.

Given these limitations, this literature review encompasses research on the mental health trajectories of people affected by the GEJE, a complex earthquake/tsunami/ nuclear disaster. Along with our review, future studies will be essential for having a better understanding of this disaster, and especially for ascertaining the long-term outcomes and their correlates.

\section{Authors' contributions}

$\mathrm{NH}$ carried out the initial literature search. $\mathrm{NH}$, JS, and KK performed the manual searches for the additional articles. $\mathrm{NH}$ and JS reviewed the potential study papers and made decisions on papers to be included. NH, JS, MT, KK, and ST drafted the manuscript. FY supervised the study process. All authors read and approved the final manuscript.

\section{Author details}

${ }^{1}$ Division of Nursing, School of Medicine, National Defense Medical College, 3-2 Namiki, Tokorozawa, Saitama 359-8513, Japan. ${ }^{2}$ William F. Connell School of Nursing, Boston College, Maloney Hall 140 Commonwealth Avenue, Chestnut Hill, MA 02467, USA. ${ }^{3}$ Department of Psychiatry, National Defense Medical College, 3-2 Namiki, Tokorozawa, Saitama 359-8513, Japan.

\section{Acknowledgements}

None.

\section{Compliance with ethical guidelines}

\section{Competing interests}

The authors declare that they have no competing interests.

Received: 8 February 2015 Accepted: 25 August 2015

Published online: 02 September 2015

\section{References}

1. Lay T, Kanamori H. Insights from the great 2011 Japan earthquake. Phys Today. 2011;64(12):33-9. doi:10.1063/PT.3.1361.

2. Yokoyama Y, Hirano K, Sato M, Abe A, Uebayashi M, Kishi E, et al. Activities and health status of dispatched public health nurses after the great East Japan earthquake. Public Health Nurs (Boston, Mass). 2014;31(6):537-44. doi:10.1111/phn.12141.

3. National Police Agency. Damage Situation and Police Countermeasures associated with 2011 Tohoku district-off the Pacific Ocean Earthquake, December 10, 2014. 2014. http://www.npa.go.jp/archive/keibi/biki/ higaijokyo_e.pdf. Accessed Dec 302014.

4. Fukushima Prefecture. Damage situation report (No. 1344) following the 2011 Tohoku district-off the Pacific Ocean Earthquake. 2015. http://www. pref.fukushima.lg.jp/uploaded/life/109612_206594_misc.xls. Accessed Jan 52015 (in Japanese).

5. Galea S, Nandi A, Vlahov D. The epidemiology of post-traumatic stress disorder after disasters. Epidemiol Rev. 2005;27:78-91. doi:10.1093/epirev/mxi003.

6. Norris FH, Friedman MJ, Watson PJ, Byrne CM, Diaz E, Kaniasty K. 60,000 disaster victims speak: Part I. An empirical review of the empirical literature, 1981-2001. Psychiatry. 2002;65(3):207-39.

7. Norris FH, Friedman MJ, Watson PJ. 60,000 disaster victims speak: Part II. Summary and implications of the disaster mental health research. Psychiatry. 2002;65(3):240-60.

8. Bromet EJ, Havenaar JM, Guey LT. A 25 year retrospective review of the psychological consequences of the Chernobyl accident. Clin Oncol. 2011;23(4):297-305. doi:10.1016/j.clon.2011.01.501.

9. Centre for Reviews and Dissemination. Systematic reviews: CRD's guidance for undertaking reviews in health care. York: Centre for Reviews and Dissemination, University of York; 2009.

10. Koyama S, Aida J, Kawachi I, Kondo N, Subramanian SV, Ito K, et al. Social support improves mental health among the victims relocated to temporary housing following the Great East Japan Earthquake and Tsunami. Tohoku J Exp Med. 2014;234(3):241-7.

11. Nagata S, Matsunaga A, Teramoto C. Follow-up study of the general and mental health of people living in temporary housing at 10 and 20 months after the Great East Japan Earthquake. Jpn J Nurs Sci Jjns. 2014;. doi:10.1111/jins.12051.

12. Niitsu T, Takaoka K, Uemura S, Kono A, Saito A, Kawakami N, et al. The psychological impact of a dual-disaster caused by earthquakes and radioactive contamination in Ichinoseki after the Great East Japan Earthquake. BMC Res Notes. 2014;7:307. doi:10.1186/1756-0500-7-307.

13. Yokoyama Y, Otsuka K, Kawakami N, Kobayashi S, Ogawa A, Tannno K, et al. Mental health and related factors after the Great East Japan earthquake and tsunami. PLoS One. 2014;9(7):e102497. doi:10.1371/journal. pone.0102497.

14. Sugimoto T, Umeda M, Shinozaki T, Naruse T, Miyamoto Y. Sources of perceived social support associated with reduced psychological distress at 1 year after the Great East Japan Earthquake: nationwide cross-sectional survey in 2012. Psychiatry Clin Neurosci. 2014;. doi:10.1111/pen.12235. 
15. Fujihara K, Saito A, Heianza Y, Gibo H, Suzuki H, Shimano H, et al. Impact of psychological stress caused by the Great East Japan Earthquake on glycemic control in patients with diabetes. Exp Clin Endocrinol Diabetes Off J Ger Soc Endocrinol Ger Diabetes Assoc. 2012;120(9):560-3. doi:10.10 55/s-0032-1314873.

16. Funayama M, Mizushima J. Severity of pre-existing psychiatric illness and response to the Great East Japan Earthquake. J Psychiatr Res. 2013;47(10):1479-82.

17. Inoue M, Matsumoto S, Yamaoka K, Muto S. Risk of social isolation among Great East Japan Earthquake survivors living in tsunami-affected Ishinomaki, Japan. Disaster Med Public Health Prep. 2014;8(4):333-40. doi:10.1017/dmp.2014.59.

18. Saito $M$. The short-term effect of the recent great earthquake on the general functioning status of psychiatric patients near Tokyo. Am J Psychiatry. 2011;168(6):649. doi:10.1176/appi.ajp.2011.11030450.

19. Aoki A, Aoki Y, Harima H. The impact of the Great East Japan earthquake on mandatory psychiatric emergency hospitalizations in Tokyo: a retrospective observational study. Transl Psychiatry. 2012;2:e168. doi:10.1038/ tp.2012.98.

20. Kato K, Mikami K, Kimoto K, Kimoto K, Takahashi Y, Sato R, et al. Changes in the frequency and clinical features of suicide attempts in the Midwestern area of Kanagawa after the Great East Japan Earthquake. J Forensic Sci. 2014;59(2):417-9.

21. Iwadare $Y$, Usami M, Ushijima H, Tanaka T, Watanabe K, Kodaira M, et al. Changes in traumatic symptoms and sleep habits among junior high school students after the Great East Japan Earthquake and Tsunami. Sleep Biol Rhythm. 2014;12(1):53-61.

22. Momma H, Niu K, Kobayashi Y, Huang C, Otomo A, Chujo M, et al. Leg extension power is a pre-disaster modifiable risk factor for post-traumatic stress disorder among survivors of the Great East Japan Earthquake: a retrospective cohort study. PLoS One. 2014;9(4):e96131. doi:10.1371/journal.pone.0096131.

23. Orui M, Harada S, Hayashi M. Changes in suicide rates in disasterstricken areas following the Great East Japan Earthquake and their effect on economic factors: an ecological study. Environ Health Prev Med. 2014;19(6):459-66. doi:10.1007/s12199-014-0418-2.

24. Takeda T, Tadakawa M, Koga S, Nagase S, Yaegashi N. Relationship between dysmenorrhea and posttraumatic stress disorder in Japanese high school students 9 months after the Great East Japan Earthquake. J Pediatr Adolesc Gynecol. 2013;26(6):355-7. doi:10.1016/j. jpag.2013.06.020

25. Takeda T, Tadakawa M, Koga S, Nagase S, Yaegashi N. Premenstrual symptoms and posttraumatic stress disorder in Japanese high school students 9 months after the great East-Japan earthquake. Tohoku J Exp Med. 2013;230(3):151-4.

26. Kuwabara H, Araki T, Yamasaki S, Ando S, Kano Y, Kasai K. Regional differences in post-traumatic stress symptoms among children after the 2011 tsunami in Higashi-Matsushima, Japan. Brain Dev. 2014;37(1):130-6. doi:10.1016/j.braindev.2014.02.003.

27. Matsubara C, Murakami H, Imai K, Mizoue T, Akashi H, Miyoshi C, et al. Prevalence and risk factors for depressive reaction among resident survivors after the tsunami following the Great East Japan Earthquake, March 11, 2011. PLoS One. 2014;9(10):e109240. doi:10.1371/journal. pone.0109240.

28. Matsumoto S, Yamaoka K, Inoue M, Muto S. Social ties may play a critical role in mitigating sleep difficulties in disaster-affected communities: a cross-sectional study in the Ishinomaki area, Japan. Sleep. 2014;37(1):13745. doi:10.5665/sleep.3324.

29. Niitsu K, Watanabe-Galloway S, Sayles H, Houfek J, Rice M. A Pilot Study of the Psychological Impact of the Great East Japan Earthquake and Tsunami. J Am Psychiatr Nurs Assoc. 2014;20(3):194-202. doi:10.1177/1078390314536615

30. Nishigori H, Sugawara J, Obara T, Nishigori T, Sato K, Sugiyama T, et al. Surveys of postpartum depression in Miyagi, Japan, after the Great East Japan Earthquake. Arch Women's Mental Health. 2014;17(6):579-81. doi:10.1007/s00737-014-0459-y.

31. Numata T, Gunfan S, Takayama S, Takahashi S, Monma Y, Kaneko S, et al. Treatment of posttraumatic stress disorder using the traditional Japanese herbal medicine saikokeishikankyoto: a randomized, observer-blinded, controlled trial in survivors of the great East Japan earthquake and tsunami. Evid Based Complement Alter Med Ecam. 2014;2014:683293. doi:10.1155/2014/683293.

32. Sekiguchi A, Sugiura M, Taki Y, Kotozaki Y, Nouchi R, Takeuchi H, et al. Brain structural changes as vulnerability factors and acquired signs of post-earthquake stress. Mol Psychiatry. 2013;18(5):618-23. doi:10.1038/ mp.2012.51.

33. Sekiguchi A, Sugiura M, Taki Y, Kotozaki Y, Nouchi R, Takeuchi H, et al. White matter microstructural changes as vulnerability factors and acquired signs of post-earthquake distress. PLoS One. 2014;9(1):e83967. doi:10.1371/journal.pone.0083967.

34. Sugiura H, Akahane M, Ohkusa Y, Okabe N, Sano T, Jojima N, et al. Prevalence of insomnia among residents of Tokyo and osaka after the great East Japan earthquake: a prospective study. Interact J Med Res. 2013;2(1):e2. doi:10.2196/ijmr.2485.

35. Tuerk PW, Hall B, Nagae N, McCauley JL, Yoder M, Rauch SA, et al. Forty days after the Great East Japan Earthquake: field research investigating community engagement and traumatic stress screening in a post-disaster community mental health training. Int J Psychiatry Med. 2013;45(2):159-74.

36. Usami M, Iwadare Y, Kodaira M, Watanabe K, Aoki M, Katsumi C, et al. Relationships between traumatic symptoms and environmental damage conditions among children 8 months after the 2011 Japan earthquake and tsunami. PLoS One. 2012;7(11):e50721. doi:10.1371/journal. pone.0050721.

37. Usami M, Iwadare Y, Watanabe K, Kodaira M, Ushijima H, Tanaka T, et al. Analysis of changes in traumatic symptoms and daily life activity of children affected by the 2011 Japan earthquake and tsunami over time. PLoS One. 2014;9(2):e88885. doi:10.1371/journal.pone.0088885.

38. Kukihara H, Yamawaki N, Uchiyama K, Arai S, Horikawa E. Trauma, depression, and resilience of earthquake/tsunami/nuclear disaster survivors of Hirono, Fukushima, Japan. Psychiatry Clin Neurosci. 2014;68(7):524-33. doi:10.1111/pen.12159.

39. Matsumoto J, Kunii Y, Wada A, Mashiko H, Yabe H, Niwa S. Mental disorders that exacerbated due to the Fukushima disaster, a complex radioactive contamination disaster. Psychiatry Clin Neurosci. 2014;68(3):182-7.

40. Rubin GJ, Amlot R, Wessely S, Greenberg N. Anxiety, distress and anger among British nationals in Japan following the Fukushima nuclear accident. Br J Psychiatry J Mental Sci. 2012;201(5):400-7. doi:10.1192/bjp. bp.112.111575.

41. Sawa M, Osaki Y, Koishikawa H. Delayed recovery of caregivers from social dysfunction and psychological distress after the Great East Japan Earthquake. J Affect Disord. 2013;148(2-3):413-7. doi:10.1016/j. jad.2012.11.011.

42. Sawa M, Takase M, Noju K, Tomiyasu T, Kawakami C, Koishikawa H, et al. Impact of the great East Japan earthquake on caregiver burden: a cross-sectional study. Psychiatr Ser (Washington, DC). 2013;64(2):189-91. doi:10.1176/appi.ps.000802012.

43. Sugimoto T, Shinozaki T, Naruse T, Miyamoto Y. Who was concerned about radiation, food safety, and natural disasters after the great East Japan earthquake and Fukushima catastrophe? A nationwide cross-sectional survey in 2012. PLoS ONE. 2014;9(9):e106377. doi:10.1371/journal. pone.0106377.

44. Tsubokura M, Hara K, Matsumura T, Sugimoto A, Nomura S, Hinata $M$, et al. The immediate physical and mental health crisis in residents proximal to the evacuation zone after Japan's nuclear disaster: an observational pilot study. Disaster Med Public Health Prep. 2014;8(1):30-6. doi:10.1017/dmp.2014.5

45. Wada A, Kunii Y, Matsumoto J, Itagaki S, Yabe H, Mashiko H, et al. Changes in the condition of psychiatric inpatients after the complex Fukushima disaster. Fukushima J Med Sci. 2013;59(1):39-42.

46. Yabe H, Suzuki Y, Mashiko H, Nakayama Y, Hisata M, Niwa S, et al. Psychological distress after the Great East Japan Earthquake and Fukushima Daiichi Nuclear Power Plant accident: results of a mental health and lifestyle survey through the Fukushima Health Management Survey in FY2011 and FY2012. Fukushima J Med Sci. 2014;60(1):57-67.

47. Goto A, Rudd RE, Lai AY, Yoshida K, Suzuki Y, Halstead DD, et al. Leveraging public health nurses for disaster risk communication in Fukushima City: a qualitative analysis of nurses' written records of parenting counseling and peer discussions. Bmc Health Ser Res. 2014;14:129. doi:10.1186/1472-6963-14-129. 
48. Ben-Ezra M, Shigemura J, Palgi Y, Hamama-Raz Y, Lavenda O, Suzuki $M$, et al. From Hiroshima to Fukushima: PTSD symptoms and radiation stigma across regions in Japan. J Psychiatr Res. 2014;60C:185-6. doi:10.1016/j.jpsychires.2014.10.006.

49. Yoshii H, Saito H, Kikuchi S, Ueno T, Sato K. Report on maternal anxiety 16 months after the great East Japan earthquake disaster: anxiety over radioactivity. Glob J Health Sci. 2014;6(6):36862. doi:10.5539/gjhs. v6n6p1.

50. Dobashi K, Nagamine M, Shigemura J, Tsunoda T, Shimizu K, Yoshino A, et al. Psychological effects of disaster relief activities on Japan ground self-defense force personnel following the 2011 great east Japan earthquake. Psychiatry. 2014;77(2):190-8. doi:10.1521/psyc.2014.77.2.190.

51. Fukasawa M, Suzuki Y, Obara A, Kim Y. Relationships between mental health distress and work-related factors among prefectural public servants 2 months after the great east japan earthquake. Int J Behav Med. 2014;. doi:10.1007/s12529-014-9392-8.

52. Matsuoka Y, Nishi D, Nakaya N, Sone T, Noguchi H, Hamazaki K, et al. Concern over radiation exposure and psychological distress among rescue workers following the Great East Japan Earthquake. BMC Public Health. 2012;12:249. doi:10.1186/1471-2458-12-249.

53. Nishi D, Koido Y, Nakaya N, Sone T, Noguchi H, Hamazaki K, et al. Fish oil for attenuating posttraumatic stress symptoms among rescue workers after the great east Japan earthquake: a randomized controlled trial. Psychother Psychosom. 2012;81(5):315-7. doi:10.1159/000336811.

54. Nishi D, Koido Y, Nakaya N, Sone T, Noguchi H, Hamazaki K, et al. Peritraumatic distress, watching television, and posttraumatic stress symptoms among rescue workers after the Great East Japan earthquake. PLoS One. 2012;7(4):e35248. doi:10.1371/journal.pone.0035248.

55. Shigemura J, Tanigawa T, Nishi D, Matsuoka Y, Nomura S, Yoshino A. Associations between disaster exposures, peritraumatic distress, and posttraumatic stress responses in Fukushima nuclear plant workers following the 2011 nuclear accident: the Fukushima NEWS Project study. PLoS One. 2014;9(2):e87516. doi:10.1371/journal.pone.0087516.

56. Shigemura J, Tanigawa T, Saito I, Nomura S. Psychological distress in workers at the Fukushima nuclear power plants. JAMA. 2012;308(7):667-9. doi:10.1001/jama.2012.9699.

57. Suzuki Y, Fukasawa M, Obara A, Kim Y. Mental health distress and related factors among prefectural public servants 7 months after the great East Japan Earthquake. J Epidemiol Jpn Epidemiol Assoc. 2014;24(4):287-94.
58. Tsutsui T, Hasegawa Y, Hiraga M, Ishiki M, Asukai N. Distinctiveness of prolonged grief disorder symptoms among survivors of the Great East Japan Earthquake and Tsunami. Psychiatry Res. 2014;217(1-2):67-71. doi:10.1016/j.psychres.2014.03.001.

59. Japan Disaster Grief Support. Japan Disaster Grief Support (JDGS) Project. 2011. http://jdgs.jp/. Accessed Jan 52015 (in Japanese).

60. Heir T, Weisaeth L. Acute disaster exposure and mental health complaints of Norwegian tsunami survivors six months post disaster. Psychiatry. 2008;71(3):266-76. doi:10.1521/psyc.2008.71.3.266.

61. Goto A, Rudd RE, Bromet EJ, Suzuki Y, Yoshida K, Suzuki Y, et al. Maternal confidence of Fukushima mothers before and after the nuclear power plant disaster in Northeast Japan: analyses of municipal health records. J Commun Healthcare. 2014;7(2):106-16. doi:10.1179/17538076 14 Y.0000000051.

62. 2003-2005 CF. Chernobyl's legacy: health, environmental and socioeconomic impacts. Vienna: International Atomic Energy Agency; 2006

63. Adams RE, Guey LT, Gluzman SF, Bromet EJ. Psychological wellbeing and risk perceptions of mothers in Kyiv, Ukraine, 19 years after the Chornobyl disaster. Int J Soc Psychiatry. 2011;57(6):637-45. doi:10.1177/0020764011415204.

64. Havenaar JM, Rumyantzeva GM, van den Brink W, Poelijoe NW, van den Bout J, van Engeland $\mathrm{H}$, et al. Long-term mental health effects of the Chernobyl disaster: an epidemiologic survey in two former Soviet regions. Am J Psychiatry. 1997;154(11):1605-7.

65. Loganovsky K, Havenaar JM, Tintle NL, Guey LT, Kotov R, Bromet EJ. The mental health of clean-up workers 18 years after the Chernobyl accident. Psychol Med. 2008;38(4):481-8. doi:10.1017/S0033291707002371.

66. Maeda M, Oe M. Disaster behavioral health: psychological effects of the Fukushima nuclear power plant accident. In: Tanigawa K, Chhem RK, editors. Radiation disaster medicine. Heidelberg: Springer; 2014. p. 79-88.

67. Ursano RJ. Post-traumatic stress disorder. N Engl J Med. 2002;346(2):1302. doi:10.1056/NEJM200201103460213.

68. McCarroll JE, Ursano RJ, Fullerton CS, Liu X, Lundy A. Somatic symptoms in Gulf War mortuary workers. Psychosom Med. 2002;64(1):29-33.

69. Ursano RJ, Fullerton CS, Vance K, Kao TC. Posttraumatic stress disorder and identification in disaster workers. Am J Psychiatry. 1999;156(3):353-9.

\section{Submit your next manuscript to BioMed Central and take full advantage of:}

- Convenient online submission

- Thorough peer review

- No space constraints or color figure charges

- Immediate publication on acceptance

- Inclusion in PubMed, CAS, Scopus and Google Scholar

- Research which is freely available for redistribution

Submit your manuscript at

www.biomedcentral.com/submit

C Biomed Central 